Article

\title{
Thermal Efficiency and Material Properties of Friction Stir Channelling Applied to Aluminium Alloy AA5083
}

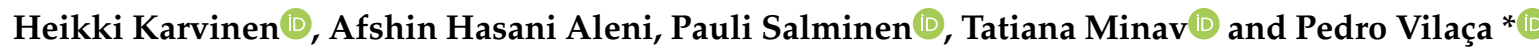 \\ Department of Mechanical Engineering, School of Engineering, Aalto University, 02150 Espoo, Finland; \\ heikki.karvinen@aalto.fi (H.K.); afshin.hasani@aalto.fi (A.H.A.); pauli.salminen@aalto.fi (P.S.); \\ tatiana.minav@aalto.fi (T.M.) \\ * Correspondence: pedro.vilaca@aalto.fi; Tel.: +358-503652110
}

Received: 21 March 2019; Accepted: 19 April 2019; Published: 24 April 2019

check for updates

\begin{abstract}
The Friction Stir Channelling (FSC) is a novel advanced solution for producing internal closed channels along any desired path with a constant or continuously modified shape along the path in a single manufacturing step. The channels are formed by continuous extraction of part of the stirred processed material into external flash. In this work, the performance of channels with the same shape and dimensions but produced by FSC and milling respectively, are compared using an experimental calorimeter setup with a focus on the influence of the geometrical features of the channels on the thermal efficiency. The investigation is implemented in a plate of AA5083-H111, with a thickness of $10 \mathrm{~mm}$. The material properties of the channels produced by FSC are investigated with a microhardness field and optical microscopic analysis, assessing the thermomechanically processed and heat affected zones. The mechanical resistance of the channels produced by FSC is evaluated with an application of internal pressure up to 380 bar. The results show that the FSC enhanced the heat transfer by about $45 \%$ compared with smoother milled channels. The optical microscopy shows evidence of a good consolidation of the solid state joining mechanisms activated during the FSC, with a small reduction of the hardness around the channel in the stirred zone and heat affected zone, being assisted by a harder top region at the ceiling of the channel.
\end{abstract}

Keywords: Friction stir channelling; cooling plate; thermal efficiency; microstructure; microhardness; internal pressure; AA5083; thermal management

\section{Introduction}

The thermal management of electric systems is one major engineering challenge that drives a great deal of research striving for solutions with higher efficiency. Thermal management and its efficiency is important in electric vehicles and in particular battery operated ones. Battery pack thermal management, especially cooling, is very important [1] to achieve high performance and to prevent failure of the battery as the variation of temperature within battery pack can cause accelerated degradation and capacity reduction of battery cells [2]. Therefore, it is important to identify a cooling method to ensure that battery cells in the pack operate in a controlled and uniform temperature range in order to maximize its pack capacity, durability and lifetime. Currently, several thermal management techniques exist to prevent overheating and uneven temperature distribution within each individual cell and across the entire battery pack during charge and discharge cycles:

- Liquid, examples: cell cooling plate [3], cells embedded in die-electric fluid [4];

- Air, examples: forced air cooling [5], natural convection [6];

- $\quad$ Phase change materials, paraffin and so forth [7]. 
Liquid cooling is typical for applications where high power density is needed. Air can be used instead of liquid [8] when the cooling application is less demanding. Depending on the cell type, different thermal management techniques should be in use to maximize contact with cooling media. For instance, cylindrical cells in direct contact with cooling fluid (air/liquid) is recommended [9] as good contact cannot be achieved with flat cooling plates. On the contrary, cooling plates are suitable for soft pouch type batteries [10] as they can be located inside the battery pack, for example, between cells [11] or modules [12] or outside the battery pack, for example, covering sides [13] or top/bottom [14,15]. Cooling by means of cooling plates in battery packs has been extensively studied. In Reference [16], cooling plates with a serpentine channel are evaluated using computational fluid dynamics in order to achieve better fluid flow and heat management. One study [17] promotes three-dimensional flow inside cooling channels using a novel channel geometry that generates chaotic advection flow. Authors in Reference [18] optimized the geometry of the internal fluid channels in a cooling plate for electric vehicle application; they determined the influence of different operating conditions on the optimum cooling plate design.

A typical limitation of most of the known studies is that they do not consider the influence of the manufacturing technique of the channels in the cooling plate. Ignoring the manufacturing technique is not sensible, namely because the surface finishing plays an important role in the efficiency of the heat transfer [19] and the different manufacturing techniques result in different surface finishing characteristics and manufacturing costs.

Therefore, the target of this study is to contribute to cover this gap by introducing a novel manufacturing technique for producing internal closed channels with a free path-the Friction Stir Channelling (FSC) —and give evaluation regarding conventional established techniques. Also, if there is a significant benefit in heat transfer efficiency of air flowing in channels produced by Friction Stir Channelling compared to other channels, then air can be used in some conditions where nowadays only liquid cooling can meet the temperature requirements of the high power density systems. Using air as cooling media has significant benefits over liquid in any application but is most significant in electric-based systems.

Established techniques, which are applied to manufacturing cooling plates, are drilling, milling, extruding, sheet metal forming, casting Additive Manufacturing (AM) and electrical discharge machining (EDM). The drilling is suitable for making the desired channel comprised of straight holes, although the tool length sets the limits for the hole depth. Weaknesses of this process application for the production of channels are the following: i) Requirement of extra holes and pipe plugs [20]; ii) Challenge to drill long holes and/or of small diameter; iii) Does not enable a conformal cooling strategy; and iv) Production of circular shapes only (which have the smallest surface to volume ratio, for the same volume of channel). The drilling and milling [21] are probably the most common techniques applied in the production of small-scale or small batch production of panels for thermal management. The milling creates open channels with different shapes and depths and a smooth surface finish. To close these channels, additional time-consuming operations needs to be applied, for example, with welding or by embedding a tailor bended tube, typically made of copper, into the milled channel of the cooling plate. However, contacting multibody-based solutions has limited efficiency due to the high thermal resistance between the components. The extrusion allows for the creation of complex cross-sections with closed channels of a smooth surface finish but at a high cost for low production volumes and only straight profiles can be manufactured [22], not enabling conformal cooling. The sheet metal forming including cutting, stamping, bending, drawing and hydroforming when combined with welding enables the production of components with internal cooling channels $[23,24]$ and these are used in mass-production also, however, these are multistage complex manufacturing solutions especially when manufacturing internal channels with complex flow paths. Producing casted components with internal closed channels and with a complex path is a highly complex process regardless of the particular casting technique used [25]. The EDM is able to produce straight channels but non-flexible tools pose a limitation to producing long and non-linear internal 
closed channels [26]. Another disadvantage of applying EDM to produce channels is the high cost due to slow manufacturing and the need for consumables.

During the last decade, a new manufacturing method was introduced which is able to create internal closed channels, with a free path, in one manufacturing step. The method is the FSC, a solid state processing technique that was firstly proposed by Mishra [27], in 2005, as a method of manufacturing heat exchangers. In the original concept, the size of the channel is rather limited as demonstrated in References [28,29]. In the original concept, the extracted material is accumulated in the gap between the tool shoulder and the original processing surface and if the gap is small the channel volume is limited, whereas if the gap is large, then there is no close die condition to close the ceiling of the channel. In 2013, a new concept enabling a wide range of internal closed channel sizes was introduced by Vilaça et al. [30]. With this new concept, the size of the channel is not limited and can even be variable along the free path. This enhancement is due to the extracted material, flowing in the viscoplastic domain, being driven outside of the processed zone and being left as detachable flash, while the shoulder is always kept in contact with original surface at the original quota, leaving the processed surface in the same original flat condition. Under this new concept, the combination of the geometrical features of the probe and shoulder and the process parameters all control the size and geometrical finishing of the channel internal surfaces. The fundamentals and parameters of the FSC technique and main features of the channels in aluminium alloy AA5083 are extensively addressed in Reference [31] and the fatigue properties characterized in References [31-34]. In this study, the FSC was applied to one monolithic plate as depicted in Figure 1.

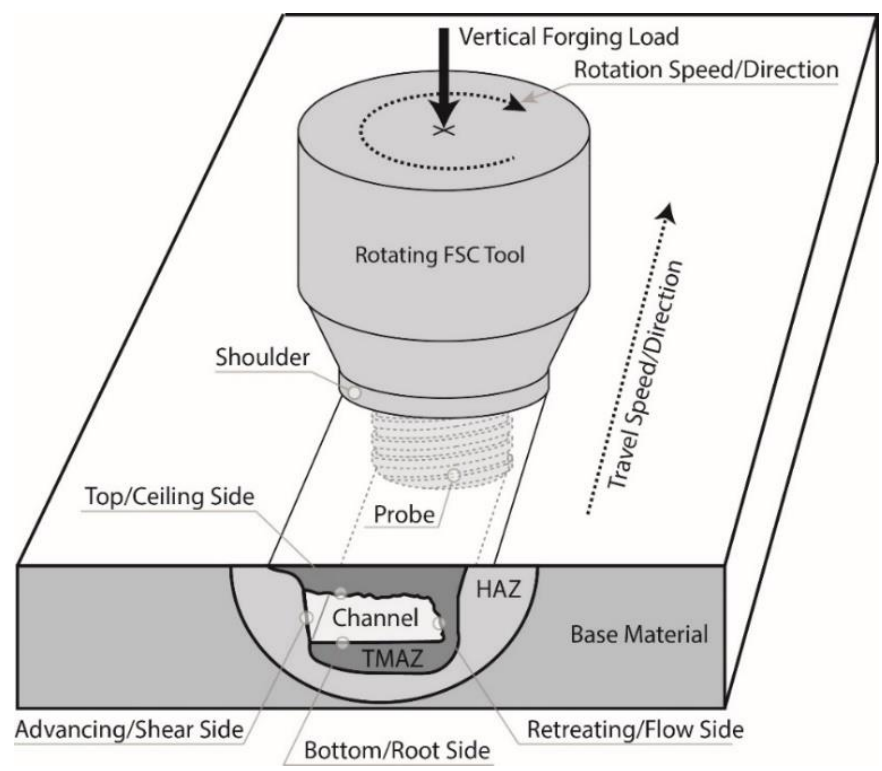

Figure 1. The rotating Friction Stir Channelling (FSC) tool, travels along the channel path, with a probe plunged into the monolithic material component and a shoulder in contact with the top surface. No tilt angle is needed to be applied between the tool and the components, enabling easy multi-direction free-path processing. The probe promotes an upward flow of the viscoplasticized material against the shoulder. The shoulder flows out, into a detachable flash, part of the viscoplasticized material and closes the channel ceiling. The channel is produced within the stirred zone of the Thermo-Mechanically Affected Zone (TMAZ) and extra heat flows through the material, generating a Heat-Affected Zone (HAZ). Adapted from [35].

FSC can be used to manufacture conformal cooling/heating systems as it is easy to produce curved channels with complex paths [36], which is important for the even distribution of heat [37]. Therefore, this technology allows application opportunities related to the manufacturing of cooling plates, namely for thermal management of EV batteries and electronic systems. 
In this paper, a novel manufacturing technique, FSC, is studied with a focus on evaluating its thermal performance in comparison with the same channel produced by a conventional milled technique. This paper is organized across six sections. Section 2 discusses the materials and experimental methods for investigation and characterization of the samples. Section 3 introduces the technological conditions of implementation of the FSC process. Section 4 addresses the characterization of the channel produced by FSC. Section 5 contains thermal efficiency analysis between FSC-channel and milled channel. Section 6 contains concluding remarks.

\section{Materials and Experimental Methods for FSC}

\subsection{Material}

Test samples with internal channels produced by milling and FSC are investigated. All the samples were produced in plates with thickness of $10 \mathrm{~mm}$, made of AA5083-H111 which is a structural aluminium alloy (Al-Mg), combining good corrosion resistance with strength. This aluminium alloy is typically used in thermal management, because it provides a lightweight solution to applications involving thermal cycles in demanding environments where corrosion resistance is a major requirement. In according to [38], the chemical composition of the AA5083-H111 is [wt. \%] 0.05-0.25 Cr; $0.1 \mathrm{Cu}$; 0.4 Fe; 4.0-4.9 Mg; 0.4-1.0 Mn; 0.4-0.7 Si; 0.15 Ti; 0.25 Zn; 0.15 Other elements; Balance with Al.

\subsection{Optical Microscopy}

Microscopy samples of the FSC channels were extracted from the channels with a disc saw perpendicular to the processing direction. The samples were mounted in the Struers MultiFast phenolic hot mounting resin using a Struers ProntoPress-20 machine. Mounted samples were ground and polished to $1 \mu \mathrm{m}$ diamond compound and etched with $10 \%$ hydrofluoric acid. Optical microscopy was performed with Nikon Epiphot 200 microscope equipped with a Nikon DS-2Mv camera. Results are presented in Figure 4.

\subsection{Hardness}

Vickers microhardness were measured in a cross section of the channel. The FSC sample was measured with a micro-combi tester from CSM Instruments. Indentation force was $500 \mathrm{gf}$ (HV05) and indentations had spacing of $1 \mathrm{~mm}$. A test matrix with a size of $10 \times 20$ indentations was applied on the sample, centred with the channel. Results are depicted in Figure 5.

\subsection{Internal Pressure}

Figure 2 illustrates schematics and pictures the utilised test setup for the internal pressure investigation. Pressure testing samples were manufactured with FSC processing parameters shown in Table 1. Flow was applied by an Enerpac P392 pump. Data was logged with a Gems 3100R0400S pressure sensor, NI USB-6218 data logger and Labview software. The pressure limit of the sensor was 400 bar, therefore, samples were pressurized up to 380 bar. Pressure was increased in steps and with a holding time between the steps. The results of pressure testing are shown in Figure 6. 


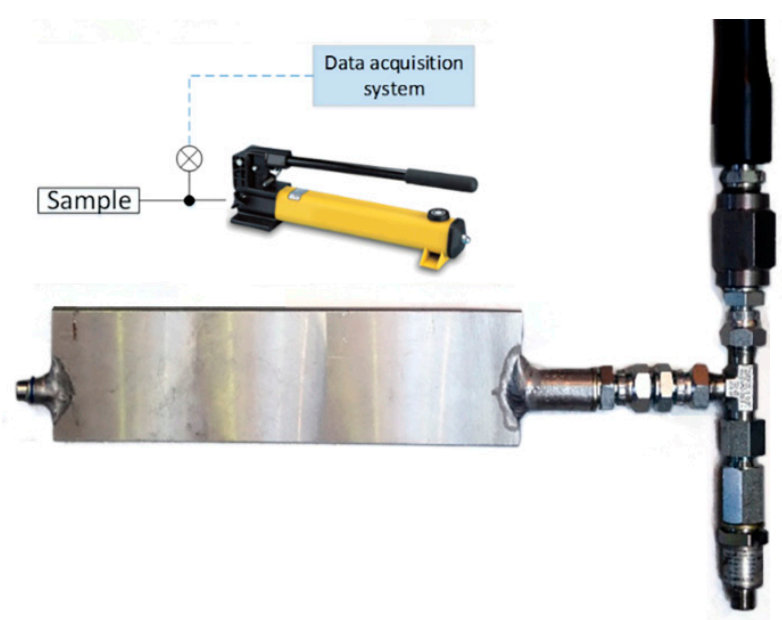

Figure 2. Schematic representation of the internal pressure test setup and picture of the test sample.

\subsection{Profilometer}

Due to the significant difference in the finishing of the surfaces of the channels produced with the FSC and milling, the measurement roughness techniques applied were distinct. A contacting profilometer by Taylor Hobson Surtronic was used to quantify the roughness of the smooth surfaces of the channel produced with the milling of the profilometer tip (Standard tip 02 by Taylor Hobson). For the extremely rough and complex surfaces of the channels produced with the FSC, an optical non-contact 3D-profilometer (GFM MikroCAD) with a height resolution of $3 \mu \mathrm{m}$ and a lateral resolution of $61 \mu \mathrm{m}$ was used to create 3D-profiles of the surface. Both techniques have their own limitations in accessing deep cavities and undercuts that are not accessible by direct light and the sensor of the profilometer. The summary of the results are presented in Table 2.

\section{Technological Application of the FSC}

FSC samples were produced with an ESAB Legio FSW 5UT welding machine. Figure 3 demonstrates a probe thread profile and an assembled FSC-tool utilized for the production of the channels. The material of the FSC tool was H13 tool steel, with a shoulder of $20 \mathrm{~mm}$ in diameter and a probe of $8 \mathrm{~mm}$ in diameter and a length of $7 \mathrm{~mm}$, with a left-hand (LH) threaded body as represented in Figure 3a.

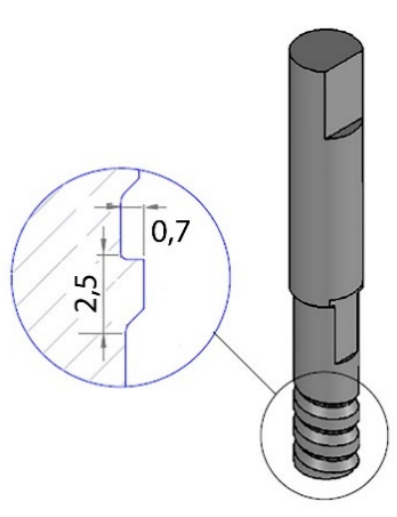

(a)

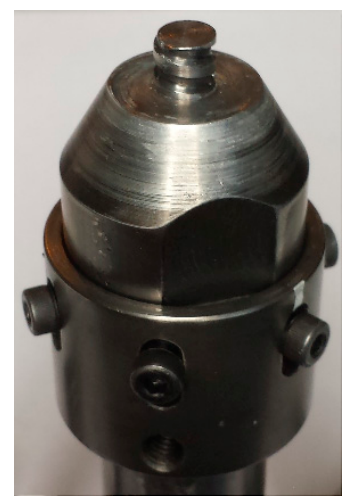

(b)

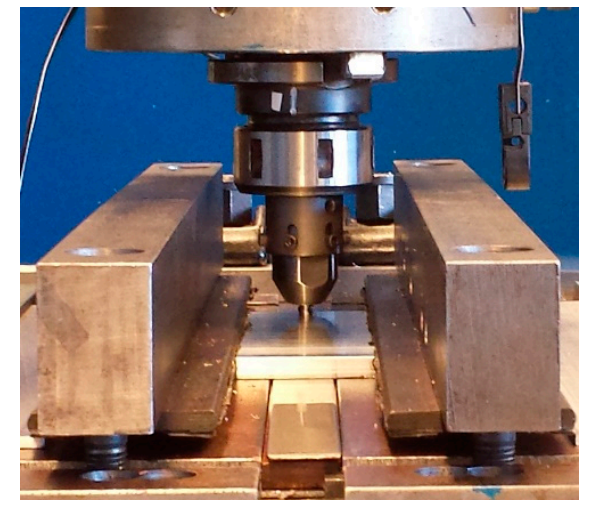

(c)

Figure 3. Technological conditions used in the application of the FSC process to the AA5083-H111 plate: (a) Specifications on probe thread profile (dimensions are in $\mathrm{mm}$ ); (b) An assembled perspective of the FSC-tool, exhibiting the shoulder and probe; (c) Clamping apparatus implemented for the production of the FSC samples. 
Table 1 depicts the parameters of the FSC process implemented in the production of the channels. The FSC process was implemented with force control. A hole $5 \mathrm{~mm}$ in diameter was drilled to a $5 \mathrm{~mm}$ depth at the starting point of the channelling in order to reduce the amount of base material expelled during the plunging period of the tool. The diameter and depth of the initial hole is smaller than the probe dimensions to assure full contact of the tool with the base material being processed at the end of the plunging period. The set of parameters were established based on the experience acquired during internal and confidential research activities outside of the scope and objectives of this investigation.

Table 1. Parameters of the FSC process implemented in the production of the channels for the samples. Parameters refer to schematics represented in Figure 1.

\begin{tabular}{cccc}
\hline $\begin{array}{c}\text { Rotation Speed } \\
{[\mathrm{rpm}]}\end{array}$ & $\begin{array}{c}\text { Rotation } \\
\text { Direction }\end{array}$ & $\begin{array}{c}\text { Travel Speed } \\
{[\mathrm{mm} / \mathbf{m i n}]}\end{array}$ & $\begin{array}{c}\text { Vertical Forging Load } \\
{[\mathbf{k N}]}\end{array}$ \\
\hline 500 & CCW & 70 & 3.1 \\
\hline
\end{tabular}

\section{Characterization of the Channel Produced by FSC}

\subsection{Optical Microscopy}

Figure 4 illustrates a macrograph, obtained via optical microscopy, of the cross-section of the FSC-channel with emphasis on some zones of metallurgical interest. Namely, 1-top (ceiling) corner of retreating side, 2-middle part of the top layer (ceiling), 3-top (ceiling) corner of the advancing side, 4-bottom corner of the advancing side, 5-middle part of the bottom and 6 - bottom corner of the retreating side.

Grain size and microstructure can be described as follows:

- Grain size is visibly smaller in the thermomechanically processed zone than in the HAZ and base material. This is a well-known characteristic in all the friction stir based processes [39,40];

- Processed zone is wider in the flow (or retreating side) and the shear (or advancing side) presents a vertical regular geometry, when compared with the retreating side that exhibits an overall wavy shaped configuration;

- The final closing zone of the channel ceiling (zone 3), at the advancing side, exhibits some alignment of oxides, that do not propagate across the thickness of the ceiling. This is due to local low level of forging pressure from the inside of the channel region. Zone 1, at the retreating side is homogeneous;

- Grain size at the middle of the channel bottom (zone 2) and top (zone 5) regions is similar. But the material flow pattern at the ceiling is distinct from the bottom. At the top (zone 2), the material flows circularly and is driven mostly by the shoulder rotation, with channel surface irregularity due to the lack of forging pressure from the inside of the channel region. At the bottom, the stirring effect is uniform and the channel surface is geometrically flat and well defined by the forging effect of the tip bottom surface of the probe. 


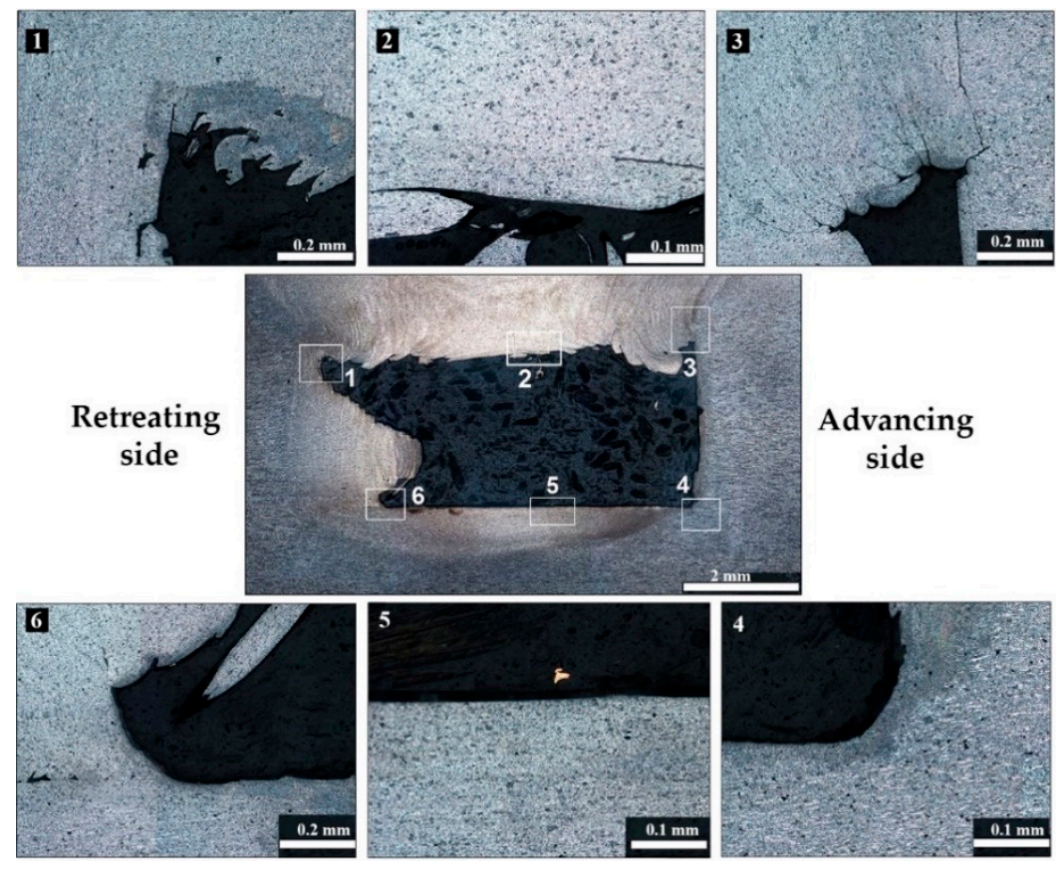

Figure 4. Macrograph of the cross-section of the channel with the identification of metallurgical zones of interest: 1-top corner of retreating side, 2-middle part of the ceiling, 3-top corner of the advancing side, 4-bottom corner of the advancing side, 5-middle part of the bottom and 6- bottom corner of the retreating side.

\subsection{Microhardness}

A microhardness map of the FSC sample is depicted in Figure 5. In general, the stirred zone and HAZ has lower hardness than the base material. Within the stirred zone, the channel top presents the higher hardness values and that fact is probably one main reason promoting the high mechanical performance of the channels. The average hardness within the stirred zone was $72 \mathrm{HV} 05$ and the maximum value was $83 \mathrm{HV} 05$.

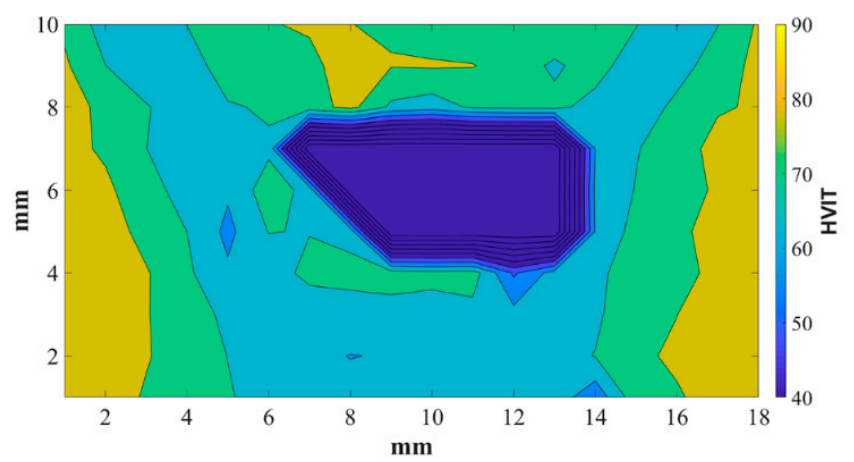

Figure 5. A HV05 microhardness map of the cross-section of the FSC sample. In the figure, the retreating side is on the left and advancing side is on the right.

\subsection{Internal Pressure Test}

The tested sample was able to withhold a pressure of 380 bar for over 1.5 hours without failure or any evident loss of pressure. The internal pressure load history presented in Figure 6 shows that FSC channels can be used in applications with high operating pressures. 

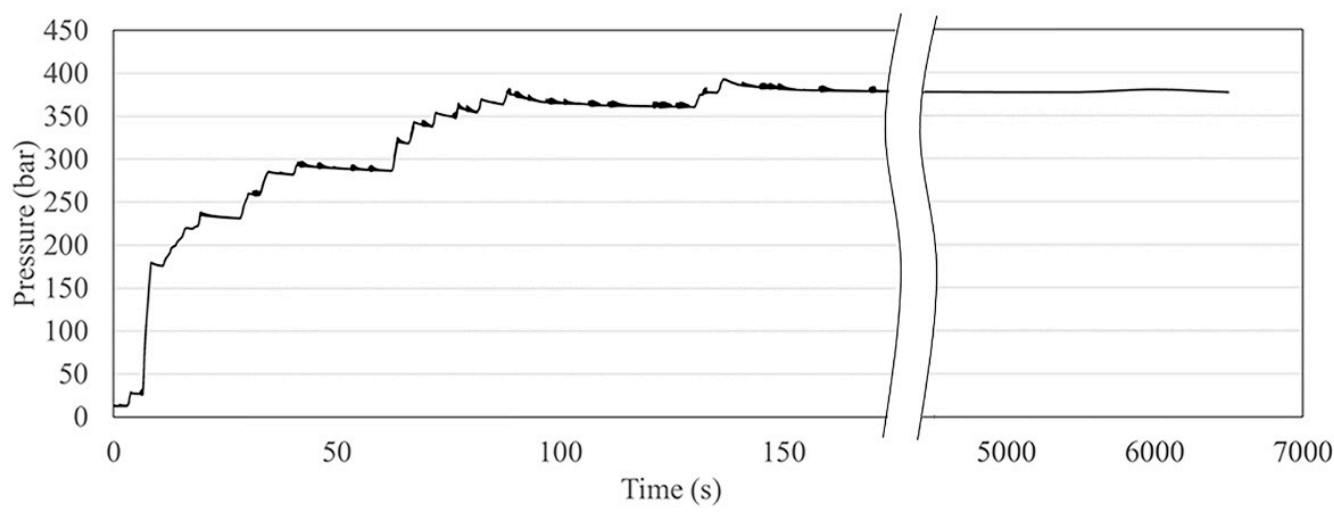

Figure 6. Pressure testing of FSC sample.

\subsection{Geometric Characterization of Channel Surfaces}

In order to analyse the distinct morphology of the internal channels produced by FSC, the parts of case samples were cut in the transversal direction (Figure 7) and opened in the longitudinal direction (Figure 8). Figure 7 demonstrates FSC-channel macrograph cross-section and FSC-channel cross-section sketch with surface names. The FSC-channel size as shown in Figure 7 a was approximately $15 \mathrm{~mm}^{2}$ $(2.5 \times 6.0 \mathrm{~mm})$. Also shown is the channel size and the area directly related to the technical parameters of the process such as traverse speed, tool rotational speed and probe penetration (Table 1).

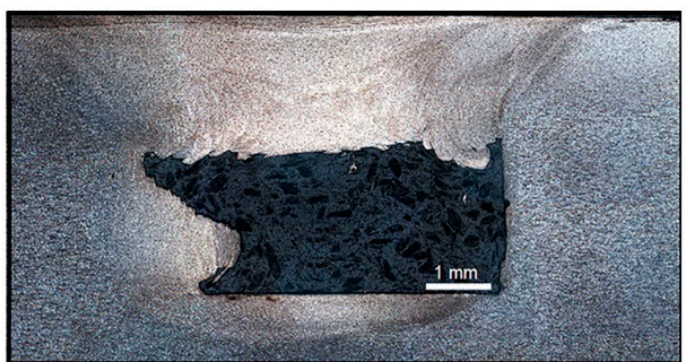

(a)

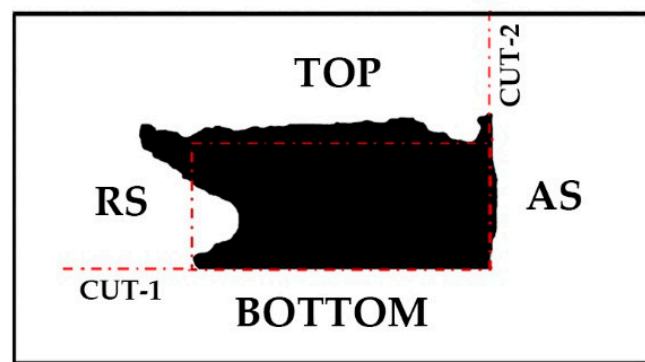

(b)

Figure 7. FSC-channel (a) macrograph cross-section; (b) cross-section sketch with surface names. EDM cut lines shown for the Figure 8.

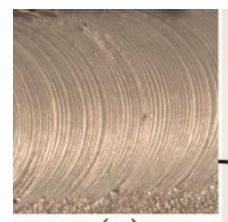

(a)

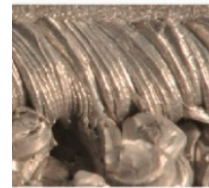

(c)

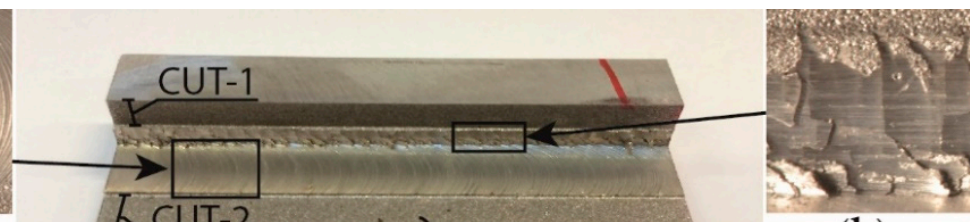

(b)

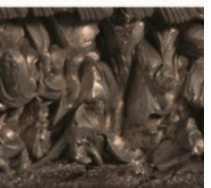

(d)

Figure 8. FSC sample cut open with electrical discharge machining (EDM). (a) Bottom is smoothest surface of the FSC-channel produced by the bottom surface of the probe tip; (b) the advancing or shear side, also quasi flat and rougher than the bottom; (c) the retreating or flow side, with a fairly rough and wavy profile along the channel depth; and (d) the top surface which is the roughest. EDM cut lines are illustrated in the Figure 7 cross-section. Adapted from [35]. 
Surface properties were analysed from the sample that was cut open by EDM. As illustrated in Figure 8, the surface topography of the channel produced by FSC is rough in this case, especially if compared with the channel size. In fact, it was intended to produce these specific channels with a higher degree of roughness than the ones presented in earlier FSC studies [41] in order to enhance heat transfer. The bottom or root side (Figure 8a) and the advancing or shear side (Figure 8b) are closest in roughness compared with the milled channels (Figure 9c) but the retreating or flow side (Figure $8 c$ ) and the top or ceiling side (Figure 8d) are higher in roughness than the milled channels. This not only increases the surface area of the channel significantly but should also create turbulent flow with multiple micro sized flow paths.

Table 2 illustrates roughness indicators for the channel surfaces, where the measurements, for the FSC channels, have been taken from the sample presented in Figure 8, according to the sections identified in Figure 7. Surface roughness has been shown to enhance convective heat transfer [42,43]. However, surface topology also alters the vortices near the surface and it has a great effect on heat transfer. According to [44], surface topology should also be considered, not only the surface roughness.

Table 2. Roughness indicators for the channel surfaces.

\begin{tabular}{cccccc}
\hline \multirow{2}{*}{ Value $[\mu \mathrm{m}]$} & \multicolumn{4}{c}{ FSC } & \multirow{2}{*}{ Milled } \\
\cline { 2 - 5 } & Top & Retreating & Advancing & Bottom & \\
\hline $\mathrm{Ra}$ & 466 & 98 & 54 & 12 & $<2$ \\
$\mathrm{Rq}$ & 575 & 129 & 69 & 16 & $<2$ \\
$\mathrm{Rsk}$ & 0.2 & 0.4 & 0.6 & 0.7 & - \\
\hline
\end{tabular}

\section{Thermal Efficiency Analysis Between FSC-channel and Milled Channel}

\subsection{Test Samples}

A set of the linear stringer samples was manufactured by milling (Figure 9a) and FSC (Figure 9b) to investigate the heat transfer properties and inherent thermal efficiency of these two different manufacturing technologies. Sample dimensions and properties for study case can be found in Table 3, where $W$ corresponds to width of the sample, $L_{\text {external }}$ to the external length and $L_{\text {channel }}$ to the length of the channel in the plate .

The method of evaluating the cross-sectional area of the internal channels produced by FSC and its level of uniformity was based on the average of eight cross sections; an example of the cross section is represented in Figure 7. The channel dimensions and height-width aspect ratio for manufacturing the milled sample was defined based on this analysis of the FSC-channel. The milled channel sample (Figure 9a) was manufactured with these dimensions. Thus, in this case the FSC and the milled channel samples have a similar size, weight and equivalent hydraulic diameters of the channel (Figure 9b). The outer dimensions of the finished FSC and milled samples are identical and the outer surface is polished on both samples (Figure 9a). Due to this, case samples are comparable and the difference in heat transfer is dictated mainly by the surface properties of the internal channel. 


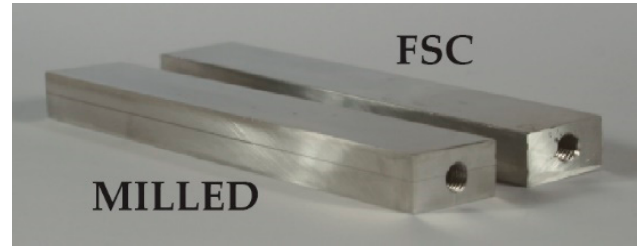

(a)

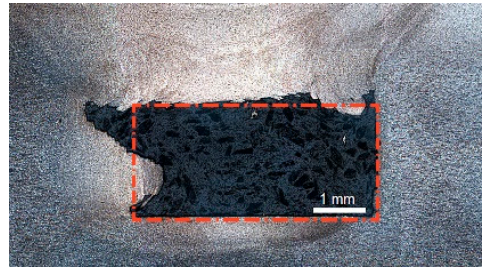

(b)

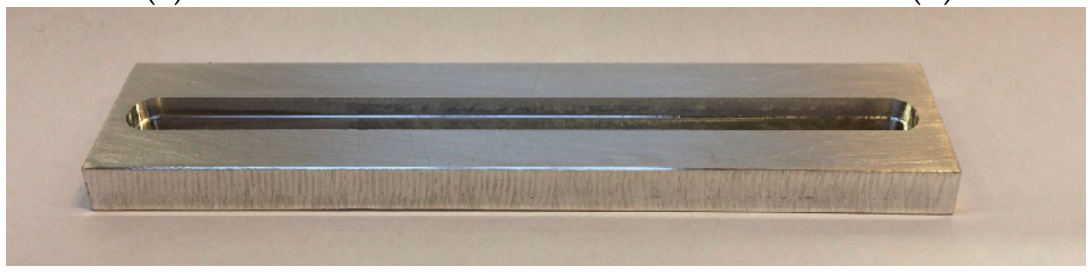

(c)

Figure 9. Milled and FSC samples: (a) The finished milled sample and the FSC sample are identical from the outer surface; (b) Outer sample dimensions are 10 (thickness) x 20 (width) x 110 (length) mm and the channel length is $100 \mathrm{~mm}$ when end fittings are excluded from outer dimensions. The cross-section from Figure 7 are used to define the size and width-height aspect ratio for the milled channel. The milled $6 \times 2.5 \mathrm{~mm}$ channel is projected on top; (c) Case study: milled sample with channel visible. The lid was adhesively bonded afterwards with thermal epoxy. The adhesive seam thickness is $<0.1 \mathrm{~mm}$.

Table 3. Dimensions of AA5083-H111 cooling plate test samples and internal channels.

\begin{tabular}{ccccccc}
\hline \multirow{2}{*}{ Sample } & \multicolumn{3}{c}{ Plate } & \multicolumn{3}{c}{ Channel } \\
\cline { 2 - 7 } & $\begin{array}{c}\text { Thickness } \\
{[\mathbf{m m}]}\end{array}$ & $\mathbf{W}[\mathbf{m m}]$ & $\begin{array}{c}\mathbf{L}_{\text {external }}[\mathbf{m m}] \\
\mathbf{L}_{\text {channel }}\end{array}$ & $\begin{array}{c}\text { Size } \\
{[\mathbf{m m}]}\end{array}$ & $\begin{array}{c}\text { Area } \\
{[\mathbf{m m} 2]}\end{array}$ \\
\hline FSC-channel & 10 & 20 & 110 & 100 & $\approx 2.5 \times 6.0^{*}$ & $\approx 15^{*}$ \\
Milled channel & 10 & 20 & 110 & 100 & $2.5 \times 6.0^{* *}$ & 15 \\
\hline
\end{tabular}

* See Figure 7. ** Outlines of the milled channel shown in Figure $9 \mathrm{~b}$.

\subsection{Experimental Setup}

Thermal exchange of the samples was measured with an adiabatic calorimeter setup as illustrated in Figure 10. The sample was located in the warm water $\left(40-60^{\circ} \mathrm{C}\right)$ inside the calorimeter having minimal thermal conduction through the walls. Air as a cooling fluid $\left(20^{\circ} \mathrm{C}\right)$ flowed in through the channel of the sample and the flow was kept constant. The experimental procedure implemented is now presented. Temperature logging and water mixing unit was started when the water was put in the calorimeter. The system was then left to stabilize for 20 minutes before coolant flow was started. Then the coolant flowed for 150 minutes. After this, the flow was cut off but the data was collected for 20 minutes more.

In this study case, a calorimeter with a water mass of $3.5 \mathrm{~kg}$ was used. Calorimeter mass was $234 \mathrm{~g}$ without the lid. The milled sample mass was $53.9 \mathrm{~g}$ and the FSC sample was $52.8 \mathrm{~g}$. Mass was measured with a laboratory scale with a measurement error of $0.1 \mathrm{~g}$. Temperatures were measured using K-type JUMO $1.5 \mathrm{~mm}$ thermocouple probes that were installed in the flow pipes or in direct contact with calorimeter water. The water bath was kept moving using a mixing unit to avoid thermal gradients. Thermocouples were connected to a National Instrument NI 9214 high-accuracy thermocouple module. Combined maximum error including RMS noise for this setup was $0.36{ }^{\circ} \mathrm{C}$ with the sensitivity of $0.01{ }^{\circ} \mathrm{C}$. The sampling rate of the thermocouple module in the high accuracy mode was $1 \mathrm{~Hz}$. 

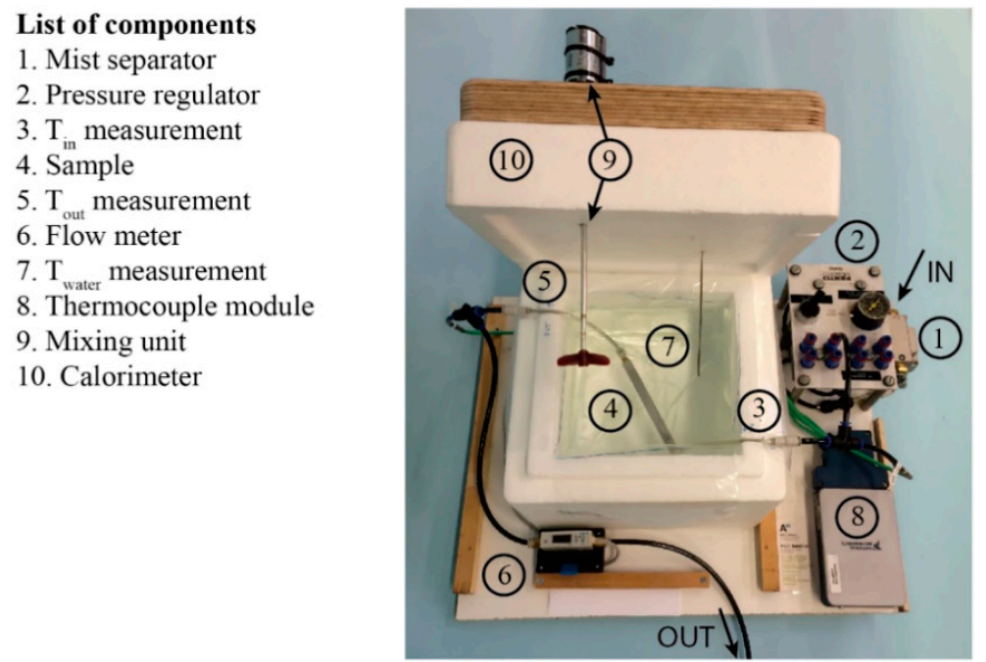

Figure 10. Test setup: Calorimeter and the components used to measure heat transfer performance of the channels. Adapted from [35].

A compressed air supply was used as a cooling fluid and its temperature varied slightly between the measurements. The air was filtered with a $0.3 \mu \mathrm{m}$ filter unit to avoid any oil or impurities entering the system and the flow was measured with a Festo SFE3-F500-Q4 flow sensor and the measurement accuracy was $5 \%$. This sensor has compensation for measurement temperature and pressure, so small fluctuations do not have an effect on the outcome. Based on the hydraulic diameter and Reynolds number, the flow was estimated to be turbulent with flows above $20 \mathrm{~L} / \mathrm{min}$. Therefore, all heat exchange measurements for straight channel samples were done with a flow of $50 \mathrm{~L} / \mathrm{min}\left(20{ }^{\circ} \mathrm{C}, 100 \mathrm{kPa}\right)$, when $\operatorname{Re}>1,4000$ based on the used equivalent hydraulic diameter.

Pressure difference over the samples was measured using the SMC PSE 530 0-M5 pressure sensors. Samples were measured three times with flow variation between $0-50 \mathrm{~L} / \mathrm{min}$. Repeatability of the sensors is less than $\pm 1 \%$ of the full scale and repeated experiments show higher accuracy than stated by the manufacturer.

As thermal energy is carried out from the calorimeter by the cooling fluid, the calorimeter inner temperature is reduced during the experiment. Temperature is measured directly from the water. Thermal capacity of the sample is negligible and calorimeter thermal capacity has only a minor effect on the thermal capacity of the whole system when compared with the thermal capacity of the water mass. Heat transfer caused by the sample and the cooling fluid can be calculated from the rate of change in water temperature over a period of time (Equation (1)). Thermal measurement has a slow response time and water movement causes minor fluctuation in the measurement. Thus, the cooling power of the sample was calculated over a time period of 360 seconds for each time step of the experiment.

$$
\dot{Q}_{\text {sample }}=\frac{m \cdot c_{p} \cdot \Delta T_{w}}{\Delta t}-\dot{Q}_{C L}
$$

where: $\dot{Q}_{\text {sample }}$ is the cooling power $[\mathrm{W}] ; c_{\mathrm{p}}$ is the specific heat capacity of water $[\mathrm{J} /(\mathrm{Kg} \cdot \mathrm{K})] ; \Delta \mathrm{T}$ is the water temperature change $[\mathrm{K}] ; \Delta \mathrm{t}$ is the time period $[\mathrm{s}]$ and $\dot{Q}_{C L}$ is calorimeter thermal loss $[\mathrm{W}]$ including conduction, convection and radiation.

As the calorimeter system is considered to be not fully adiabatic, the utilized measurement procedure was used without coolant flow to define calorimeter thermal loss through the whole calorimeter unit. As measurement through the whole temperature range is slow, a mathematical model was established to calculate the compensation across the whole measurement range. This model was verified with long measurements starting at certain temperatures. The calorimeter thermal loss was found to be $1.3-2.7 \mathrm{~W}$ at a temperature range of $30-40{ }^{\circ} \mathrm{C}$. Calorimeter thermal loss was calculated for 
each time step and it is deducted from the total thermal power extracted as seen in Equation (1). Thus, the results show only the thermal loss caused by the coolant flow through the sample.

The total heat transfer error for this setup was $\pm 1 \%$ which was calculated from measurement errors. Differences in heat transfer rate of the samples can be defined and compared with this setup because the measurement setup and conditions are the same.

\subsection{Experimental Thermal Results}

The two samples with straight stringer channels, shown in Figure 9a, were tested. The measurement results of the samples are repeatable. During the experiment, calorimeter water temperature drops (as shown in Figure 11) as the coolant flowing in the channel of the sample transfers heat. With a higher heat transfer rate, the calorimeter water temperature gradient is steeper. Average coolant temperatures are given in the Figure 11.

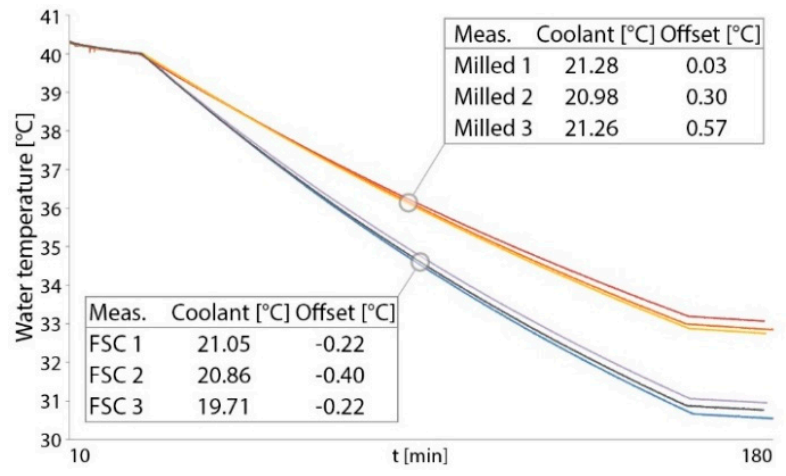

Figure 11. Calorimeter water temperature for six experiments. Coolant average temperature varies slightly with the ambient temperature. Offset is used for the lines to set $40^{\circ} \mathrm{C}$ as an initial temperature for the moment when the coolant flow is started. Coolant flow is $50 \mathrm{~L} / \mathrm{min}\left(20^{\circ} \mathrm{C}, 101 \mathrm{kPa}\right)$. Calorimeter heat loss can be seen in flat curves before and after the coolant flow has been started. These values can be used to determine calorimeter loss. Adapted from [35].

The cooling power of the sample for each time step was calculated directly with the information from Figure 11. However, the cooling rate of calorimeter water differs with FSC and milled samples. Thus, comparison of the cooling power of the samples must be made when the temperature difference between the coolant and calorimeter water is the same for both samples (Figure 12a). A cooling power comparison chart (Figure 12b) was drawn for comparison. Figure $12 b$ demonstrates a $45 \%$ $( \pm 1 \%)$ higher cooling power of FSC-channel compared with the milled sample in similar conditions. The dashed line in Figure 12b is the harmonic mean of the measurement sets with a 2SD (95\%) error bar. The results also illustrate that the rough surface of the FSC creates vortices on the channel surface, which increases heat transfer. However, vorticity and turbulence increases the friction in the flow, thus increasing the pressure loss over the channel length. Pressure difference measurement (illustrated in Figure 13) for the case study samples indicate $36 \%( \pm 1 \%)$ an increase in pressure loss for the FSC sample and the milled sample. 


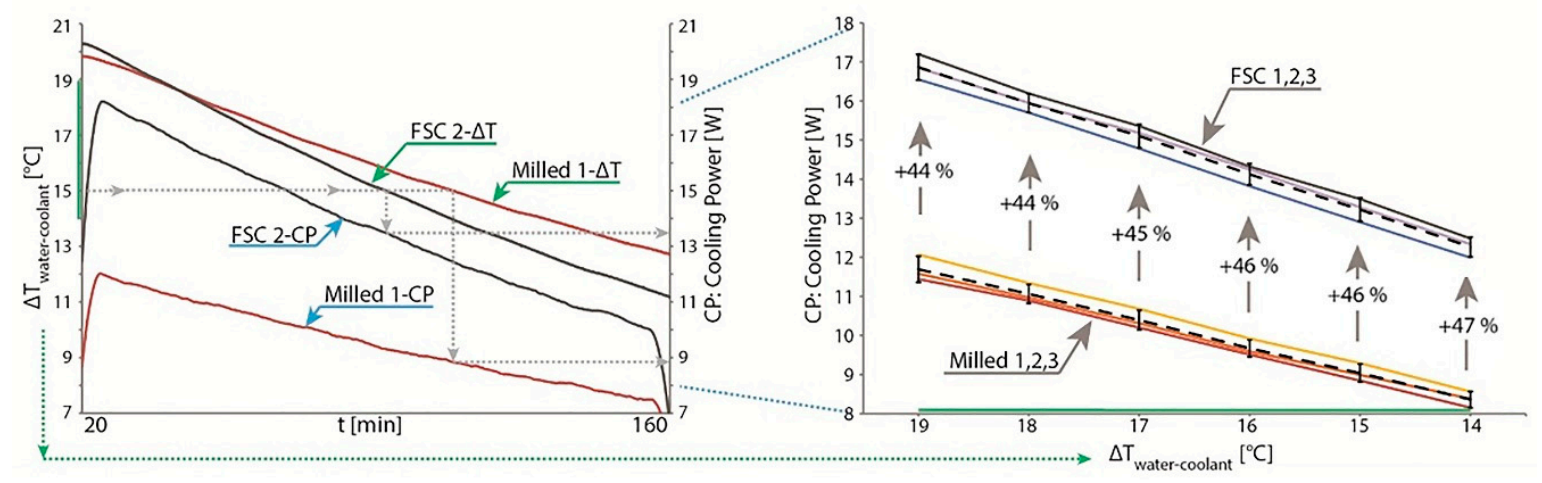

(a)

(b)

Figure 12. (a) Cooling Power (CP) of case study samples compared in similar thermal conditions. (b) Cooling power for FSC and milled samples with similar temperature difference of calorimeter water and coolant flow. Adapted from [35].

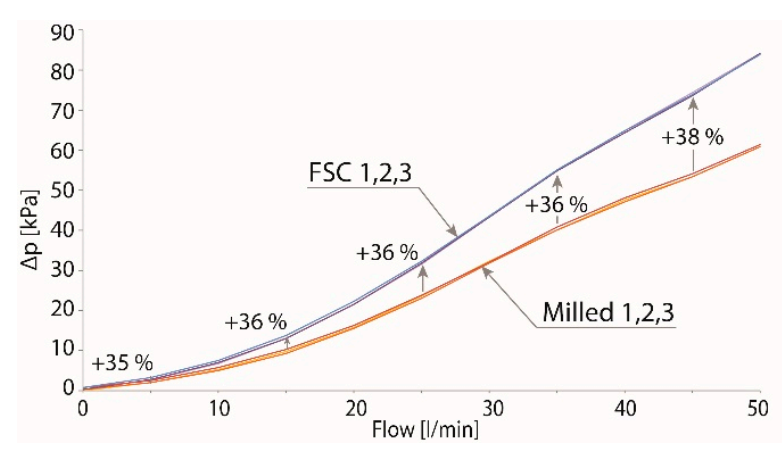

Figure 13. Pressure difference over the FSC and milled samples with 0-50 1/min flow for case study samples. Adapted from [35].

The results of the surface roughness investigation show that the different walls of the FSC channel have major differences in roughness pattern. The FSC manufacturing conditions for the samples used in this study resulted in a very rough surface. However, it is known from previous implementations using the same material that FSC-channels can be manufactured to be smoother [32] if needed. In fact, as heat transfer varies according to surface roughness and morphology of the channel, the heat transfer in channels produced by FSC can be continuously modified over the length by varying the manufacturing parameters such as travel and rotation speed and forging force. In the near future, FSC could become a unique manufacturing method to produce a complex path channel with varying heat transfer rate along the channel length in one manufacturing step.

\section{Conclusions}

This paper investigates the heat transfer capacity rate with air flowing within closed channels made by conventional milling and the innovative process FSC. The samples were produced with similar size and shape, with the major difference being the manufacturing method and thus the surface finish of the channel. The surface of the channels obtained with FSChas higher roughness when compared with the milled channel. Based on the thermal efficiency analysis and characterization of the channel produced by FSC, the following main conclusions are possible to draw:

- The optical microscopy analysis shows the roughness of the different channel surfaces as a result of the different forging conditions. The top surface of the channel presents some unbonded regions and alignment of oxide particles at the advancing side but most of the thickness of the ceiling layer of the channel is sound and well consolidated; 
- The stirred zone and HAZ exhibits lower hardness than the base material but the channel top layer presents somewhat higher hardness values. This fact is probably a key contributor to the high mechanical performance of the channels, as evidenced by the internal pressure test, with the channels withstanding 380 bar for a long period without any leak;

- The surface finishing analysis shows relatively smoother surfaces at the bottom and shear sides and highly rough surfaces at the ceiling and retreating sides. But the roughness in all surfaces is considerably higher than the ones obtained in channels produced by milling;

- The turbulent air cooling channels produced with FSC presented a $45 \%$ higher heat power dissipation capacity when compared with the ones produced by milling. The channels produced with FSC had an increased pressure loss of about $36 \%$.

Author Contributions: For conceptualization, P.V. and T.M.; manufacturing FCS plates, A.H.A.; thermal analysis, P.S.; channel characterization, H.K.; internal pressure test, H.K. and T.M.; writing-original draft preparation, P.S., T.M., P.V. and H.K.; supervision, P.V.

Funding: The research was enabled by the financial support of ECV eStorage-project (Tekes, the Finnish Funding Agency for Technology and Innovation) and internal funding from the Department of Mechanical Engineering of School of Engineering of Aalto University, Finland.

Conflicts of Interest: The authors declare no conflict of interest.

\section{References}

1. Severino, B.; Gana, F.; Palma-Behnke, R.; Estevez, P.A.; Calderón-Muñoz, W.R.; Orchard, M.E.; Reyes, J.; Cortés, M. Multi-objective optimal design of lithium-ion battery packs based on evolutionary algorithms. J. Power Sources 2014, 267, 288-299. [CrossRef]

2. Waldmann, T.; Wilka, M.; Kasper, M.; Fleischhammer, M.; Wohlfahrt-Mehrens, M. Temperature dependent ageing mechanisms in Lithium-ion batteries-A Post-Mortem study. J. Power Sources 2014, 262, 129-135. [CrossRef]

3. Giuliano, M.R.; Advani, S.G.; Prasad, A.K. Thermal analysis and management of lithium-titanate batteries. J. Power Sources 2011, 196, 6517-6524. [CrossRef]

4. Shekhar Sharma, C.; Tiwari, M.K.; Zimmermann, S.; Brunschwiler, T.; Schlottig, G.; Michel, B.; Poulikakos, D. Energy efficient hotspot-targeted embedded liquid cooling of electronics. Appl. Energy 2015, 138, 414-422. [CrossRef]

5. Xu, X.M.; He, R. Research on the heat dissipation performance of battery pack based on forced air cooling. J. Power Sources 2013, 240, 33-42. [CrossRef]

6. Sun, H.; Dixon, R. Development of cooling strategy for an air cooled lithium-ion battery pack. J. Power Sources 2014, 272, 404-414. [CrossRef]

7. Hemery, C.-V.; Pra, F.; Robin, J.-F.; Marty, P. Experimental performances of a battery thermal management system using a phase change material. J. Power Sources 2014, 270, 349-358. [CrossRef]

8. Cho, G.Y.; Choi, J.W.; Park, J.H.; Cha, S.W. Transient modeling and validation of lithium ion battery pack with air cooled thermal management system for electric vehicles. Int. J. Automot. Technol. 2014, 15, 795-803. [CrossRef]

9. Jarret, A.; Kim, I.Y. Influence of operating conditions on the optimum design of electric vehicle battery cooling plates. J. Power Sources 2014, 245, 644-655. [CrossRef]

10. Kim, Y.; Mohan, S.; Siegel, J.B.; Stefanopoulou, A.G.; Ding, Y. The estimation of temperature distribution in cylindrical battery cells under unknown cooling conditions. IEEE Trans. Control Syst. Technol. 2014, 22, 2277-2286.

11. Yuah, H.; Wang, L.; Wang, L. Battery thermal management system with liquid cooling and heating in electric vehicles. J. Automot. Saf. Energy 2012, 3, 371-380.

12. Yeow, K.; Teng, H.; Thelliez, M.; Tan, E. Comparative study on thermal behavior of lithium-ion battery systems with indirect air cooling and indirect liquid cooling. In Proceedings of the ASME, St. Louis, MO, USA, 18-20 June 2012; pp. 585-591. 
13. Yeow, K.; Teng, H.; Thelliez, M.; Tan, E. Thermal analysis of a li-ion battery system with indirect liquid cooling using finite element analysis approach. SAE Int. J. 2012, 1, 65-78. [CrossRef]

14. Nieto, N.; Díaz, L.; Gastelurrutia, J.; Blanco, F.; Ramos, J.C.; Rivas, A. Novel thermal management system design methodology for power lithium-ion battery. J. Power Sources 2014, 272, 291-302. [CrossRef]

15. Adegbohun, F.; von Jouanne, A.; Lee, K.Y. Autonomous Battery Swapping System and Methodologies of Electric Vehicles. Energies 2019, 12, 667. [CrossRef]

16. Smith, J.; Hinterberger, M.; Hable, P.; Koehler, J. Simulative method for determining the optimal operating conditions for a cooling plate for lithium-ion battery cell modules. J. Power Sources 2014, 267, 784-792. [CrossRef]

17. Yua, S.H.; Sohna, S.; Hyun Nam, J.; Kim, C.-J. Numerical study to examine the performance of multi-pass serpentine flow-fields for cooling plates in polymer electrolyte membrane fuel cells. J. Power Sources 2009, 194, 697-703. [CrossRef]

18. Lasbet, Y.; Auvity, B.; Castelain, C.; Peerhossaini, H. A chaotic heat-exchanger for PEMFC cooling applications. J. Power Sources 2006, 156, 114-118. [CrossRef]

19. Neubauer, J.; Wood, E. Thru-life impacts of driver aggression, climate, cabin thermal management, and battery thermal management on battery electric vehicle utility. J. Power Sources 2014, 259, 262-275. [CrossRef]

20. Andrade, J., Jr.; Henrique, E.; Almeida, M.; Costa, M. Heat transport through rough channels. Physica A 2004, 339, 296-310. [CrossRef]

21. Hamade, R.F.; Ismail, F. A case for aggressive drilling of aluminum. J. Mater. Process. Technol. 2005, 166, 86-97. [CrossRef]

22. Schulze, V.; Becke, C.; Weidenmann, K.; Dietrich, S. Machining strategies for hole making in composites with minimal workpiece damage by directing the process forces inwards. J. Mater. Process. Technol. 2011, 211, 329-338. [CrossRef]

23. Vollertsen, F.; Sprenger, A.; Kraus, J.; Arnet, H. Extrusion, channel, and profile bending: A review. J. Mater. Process. Technol. 1999, 87, 1-27. [CrossRef]

24. Weber, D.; Spencer, S.; Spacher, P. Battery Cooling Plate Design with Discrete Channels. U.S. Patent No. US 7851080 B2, 14 December 2010.

25. Campbell, J. Complete Casting Handbook-Metal Casting Processes, Metallurgy, Techniques and Design; Butterworth-Heinemann: Oxford, UK, 2011; p. 1142.

26. Leão, F.N.; Pashby, I.R.; Cuttell, M.; Lord, P. Optimisation of EDM fast hole-drilling through evaluation of dielectric and electrode materials. In Proceedings of the ABCM, Ouro Preto, Brazil, 6-11 September 2005; pp. 1-8.

27. Mishra, R.S. Integral Channels in Metal Components and Fabrication Thereof. US. Patent No. US 6923362 B2, 2 August 2005.

28. Balasubramanian, N. Friction Stir Channeling: An Innovative Technique. Ph.D. Thesis, Missouri University of Science and Technology, Rolla, MO, USA, 2008.

29. Balasubramanian, N.; Mishra, R.S.; Krishnamurthy, K. Friction stir channeling: Characterization of the channels. J. Mater. Process. Technol. 2009, 209, 3696-3704. [CrossRef]

30. Vilaça, P.; Vidal, C. Process of Opening Internal Continuous Channels in Massive Components without Changing the Original Position of the Processed Surface and Respective Modular Adjustable Tool. International Patent No. PT 105628, 19 September 2013.

31. Vidal, C. Development and Mechanical Characterization of a New Manufacturing Technology: Friction stir Channeling. Ph.D. Thesis, Technical University of Lisbon, Lisbon, Portugal, 2015.

32. Vidal, C.; Infante, V.; Vilaça, P. Fatigue assessment of friction stir channels. Int. J. Fatigue 2014, 62, 77-84. [CrossRef]

33. Vidal, C.; Infante, V.; Vilaça, P. Fatigue behaviour at elevated temperature of friction stir channeling solid plates of AA5083-H111 aluminium alloy. Int. J. Fatigue 2014, 05, 85-92. [CrossRef]

34. Vidal, C.; Infante, V.; Vilaça, P. Characterisation of fatigue fracture surfaces of friction stir channeling specimens tested at different temperatures. Eng. Failure Anal. 2015, 56, 204-215. [CrossRef]

35. Salminen, P. Improving Mechanical and Thermal Design of New Energy Production Systems. Ph.D. Thesis, Aalto University, Aalto, Finland, 2017. 
36. Ferraz, M. Friction stir Channeling Industrial Applications-Prototype Design and Production. Master's Thesis, Technical University of Lisbon, Lisbon, Portugal, 2012.

37. Woodbank Communications. Battery and Energy Technologies, Thermal Management. 2015. Available online: http://www.mpoweruk.com/thermal.htm (accessed on 2 April 2015).

38. EN 573-3 Aluminium and Aluminium Alloys. Chemical Composition and Form of Wrought Products. Part 3: Chemical Composition and Form of Products; European Committee for Standardization: Brussels, Belgium, 2013.

39. Mishra, R.S.; Ma, Z.Y. Friction stir welding and processing. Mater. Sci. Eng. 2005, 50, 1-78. [CrossRef]

40. Fonda, R.W.; Bingert, J.F.; Colligan, K.J. Texture and Grain Evolutions in a 2195 Friction Stir Weld. In Proceedings of the 5th International Friction Stir Welding Symposium, Metz, France, 14-16 September 2004.

41. Hasani, A. Development of Technological Conditions and Applications of Friction stir Channeling. Master's Thesis, Aalto University, Aalto, Finland, 2014.

42. Ventola, L.; Robotti, F.; Dialameh, M.; Calignano, F.; Manfredi, D.; Chiavazzo, E.; Asinari, P. Rough surfaces with enhanced heat transfer for electronics cooling by direct metal laser sintering. Int. J. Heat Mass Transf. 2014, 75, 58-74. [CrossRef]

43. Ventola, L.; Scaltrito, L.; Ferrero, S.; Maccioni, G.; Chiavazzo, E.; Asinari, P. Micro-structured rough surfaces by laser etching for heat transfer enhancement on flush mounted heat sinks. J. Phys. Conf. Ser. 2014, 525, 1-10. [CrossRef]

44. Ma, C.; Chen, X.; Wang, J.; Zang, S.; Ji, Y. An experimental investigation of heat transfer characteristics for steam cooling in a rectangular channel with parallel ribs. J. Therm. Sci. 2014, 23, 454-464. [CrossRef]

(C) 2019 by the authors. Licensee MDPI, Basel, Switzerland. This article is an open access article distributed under the terms and conditions of the Creative Commons Attribution (CC BY) license (http://creativecommons.org/licenses/by/4.0/). 